secreted then degraded by endogenous proteases, because placental annexin 4 was not degraded when added to prostate fluid and incubated at $37^{\circ} \mathrm{C}$. The collective concentrations of annexin 1, des-(1-29)-annexin 1 , and annexin 5 in prostate fluid and seminal plasma were $1.3 \%$ and $0.2 \%$ of the total protein, respectively. This is consistent with their secretion by the prostate and subsequent dilution of seminal vesicle fluid.

\section{Summary}

The human prostate expresses very high concentrations of annexins 1,4 , and 5 and secretes high concentrations of annexins 1 and 5 . Although the biological roles of these proteins in prostate secretions are not known, these studies emphasize the need to consider extracellular sites for physiological functions of annexins. The clear demonstration of secretion of proteins that have blocked $N$-termini and lack hydrophobic signal sequences raises the possibility that novel cellular secretory pathways exist. Preliminary immunohistochemical experiments in collaboration with Dr James Fallon indicate that both annexins 1 and 4 are expressed in prostate ductal secretory epithelium. Since annexin 1 , but not annexin 4 , is secreted, a comparison of the cellular fate of these two related proteins in the prostate may provide a useful model system for determining the structural elements that direct the secretion of proteins which lack conventional signal sequences.

1. Crompton, M. R., Moss, S. E. \& Crumpton, M. J. (1988). Cell (Cambridge, Mass.) 55, 1-3
2. Crumpton, M. J. \& Dedman, J. R. (1990) Nature (London) 345 , 212

3. Haigler, H. T., Schlaepfer, D. D. \& Burgess, W. H. (1987) J. Biol. Chem. 262, 6921-6930

4. De, B. K., Misono, K. S., Lukas, T., Mroczkowski, B. \& Cohen, S. (1986) J. Biol. Chem. 26 1, 13784-13792

5. Pepinsky, R. B. \& Sinclair, L. K. (1986) Nature (London) 321 , $81-84$

6. Glenney, J. R. \& Tack, B. F. (1985) Proc. Natl. Acad. Sci. U.S.A. 82, 7884-7888

7. Schlaepfer, D. D. \& Haigler, H. T. (1988) Biochemistry 27, 4253-4258

8. Pepinsky, R. B., Tizard, R.. Mattaliano, R. J., Sinclair, L. K., Miller, G. T., Browning, J. L., Chow, E. P., Burne, C., Huang, K.-S., Pratt, D., Wachter, L., Hession. C., Frey, A. Z. \& Wallner, B. P. (1988) J. Biol. Chem. 263, 10799-10811

9. Pepinsky, R. B., Sinclair, L. K., Browning, J. L., Mattaliano, R. J., Smart, J. E., Chow, E. P., Falbel, T., Ribolini, A., Garwin, J. L. \& Wallner, B. P. (1986) J. Biol. Chem. 261, 4239-4246

10. Muesch, A., Hartmann, E., Rohde, K., Rubartelli, A., Sitia, R.\& Rapoport, T. A. (1990) Trends Biochem Sci 15, 86-88

11. Berruti, G. (1988) Exp. Cell Res. 179. 374-384

12. Lizana, J., Eneroth, P., Bystrom, B. \& Bygdeman, M. (1987) Int. J. Fertil 32, 71-76

13. Ando, Y., Imamura, S., Hong, Y.-M., Owada, M. K., Kakunaga, T. \& Kannagi, R. (1989) J. Biol. Chem. 264, 6948-6955

14. Huang, K.-S., McGray, P., Mattaliano, R. J. Burne, C., Chow, E. P., Sinclair, L. K. \& Pepinsky, R. B. (1987) J. Biol. Chem. 262, 7639-7645

15. Spring-Mills, E. \& Hafez, E. S. E. (1980) in Human Reproduction (Hafez, E. S. E., ed.), pp. 60-90, Harper and Row, Cambridge

Received 13 July 1990

\title{
Tyrosine kinase substrate annexin II (p36) - biochemical characterization and conservation among species
}

\section{VOLKER GERKE}

Max Planck Institute for Biophysical Chemistry, Department of Biochemistry, D-3400 Göttingen, F.R.G.

\section{Introduction}

Annexin II (p36) is a member of the annexin family of $\mathrm{Ca}^{2+}$ - and phospholipid-binding proteins (for review see $[1-5]$ ). Like other proteins which belong to this multigene family, annexin II shows a characteristic structural feature, the so-called annexin repeat. This term describes a segment 70-80 amino acids in length which is repeated four times along the annexin Il polypeptide chain. The annexin repeats exhibit homologies with one another not only within annexin II but also with other members of the family [1-5]. Typically, a given repeat shows a higher degree of conservation between distinct members of the family than to other repeats in the same protein. The sum of the four repeats in annexin II forms the so-called protein core, which is resistant to mild proteolytic treatment. In the primary structure, this core is preceded by a proteinase-sensitive $N$-terminal tail, some 30 residues in length. Biochemical characterization of the proteolytic derivatives revealed that the protein core harbours binding sites for $\mathrm{Ca}^{2+}$, phospholipids and cytoskeletal proteins, such as F-actin and non-erythroid spectrin. Since the ability to interact with phospholipids in a $\mathrm{Ca}^{2+}$-dependent manner is shared with all other annexins, it is believed that a highly conserved stretch of 17 amino acids (the so-called endonexin fold), which is found in each annexin repeat of every member of the family, is involved in the interaction with these ligands. The $\mathrm{N}$-terminal tail of annexin II is not required for $\mathrm{Ca}^{2+}$, phospholipid- or F-actin-binding, but harbours different phosphorylation sites and thus is believed to represent an important regulatory region of the molecule. Tyr-23 is phosphorylated by pp60 $60^{s r}$, while Ser-25 is a site for protein kinase C phosphorylation. Consequently, annexin II was originally identified as a major cytoplasmic substrate for the src-encoded tyrosine kinase (for review see [6]).

Annexin II is so far the only annexin which has been shown to interact with a cellular protein ligand, pl 1, both in vitro and in vivo (for review see [3]). Interaction leads to the formation of a tetrameric complex, which comprises two annexin II and two pl1 chains. pl 1 binding is probably an important regulatory event, since it modulates properties displayed by annexin II. While monomeric annexin II shows $50 \%$ binding to liposomes at $10 \mu \mathrm{M}$-free $\mathrm{Ca}^{2+}$, annexin II complexed with p11 only needs $10 \mathrm{nM}^{-\mathrm{Ca}^{2+}}$ for the same interaction [7]. Similarly, the annexin II-p 11 complex is able to induce chromaffin granule aggregation and even fusion of these vesicles at much lower $\mathrm{Ca}^{2+}$ concentrations than monomeric annexin II [8]. The pl1-binding site is also located within the $N$-terminal tail of annexin II. However, while the phosphorylation sites cluster between residues 20 and 30 , only the $12 \mathrm{~N}$-terminal amino acids are required for p11 binding. This region of the molecule forms an amphipathic helix with the hydrophilic face of this helix probably being the actual $p 11$ contact site [9].

p11 itself belongs to a different multigene family showing sequence homologies to the $\$ 100$ proteins and other related polypeptides like calcyclin or the calgranulins (for review see [10]). Members of this protein family are characterized by 
the existence of two classical $\mathrm{Ca}^{2+}$-binding loops, the socalled EF-hand structures. However, while S100, calcyclin and calgranulin bind $\mathrm{Ca}^{2+}$ in vitro, $\mathrm{p} 11$ has lost this property owing to crucial amino acid deletions or substitutions in the two putative $\mathrm{Ca}^{2+}$ loops.

To describe structural parameters which are involved in the binding of different ligands $\left(\mathrm{Ca}^{2+}\right.$, phospholipid, p 1 1) to annexin II, we started to determine the conservation of annexin II and pll sequences among species. Here, complete cDNA sequences for annexin II and 111 from two different non-mammalian species, Gallus domesticus and Xenopus laevis, are reported. Interestingly, annexin II shows a much higher degree of conservation than pl 1 .

\section{Idenification of annexin II and its cellular ligand, pll, in different species}

To identify annexin II and p11 in different non-mammalian species, total cellular proteins from various cells were analysed for the existence of cross-reacting polypeptides in immunoblots. As shown in Fig. I (lanes 1, 2), monoclonal antibodies raised against porcine annexin 11 and $\mathrm{pl} l(\mid 11)$ kindly provided by Dr M. Osborn, Max Planck Institute, Göttingen, F.R.G.) clearly demonstrate the presence of the respective proteins in chicken embryo fibroblasts. In addition, earlier biochemical studies had revealed that a p36-p 11 complex could be purified from chicken intestinal epithelium following a procedure developed for the mammalian proteins $(12 \mid$. Owing to this conservation of biochemical properties and antigenic determinants, chicken annexin II and $p 11$ are likely to be highly similar in primary structure to their mammalian counterparts.

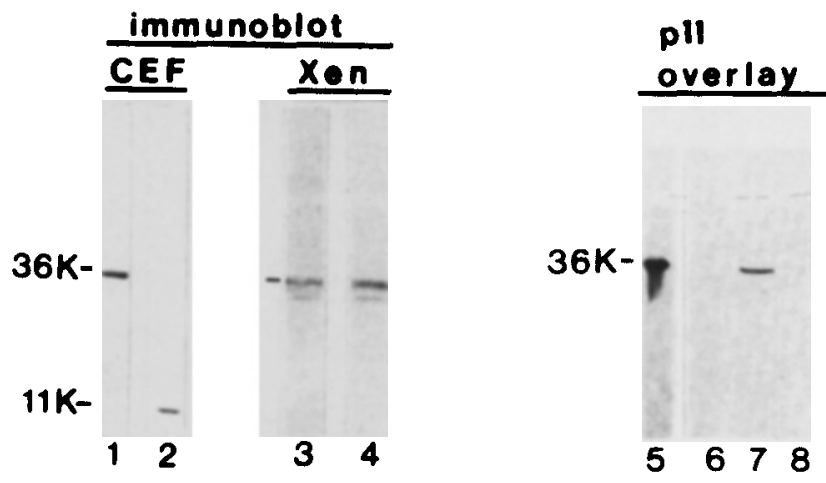

Fig. 1. Identification of annexin II and pII in different species

Total cellular proteins from chicken embryo fibroblasts (lanes 1,2 ), $X$. laevis A6 cells (lanes, 3, 4, 7). Drosophila melamogaster S3 cells (lane 6) or Dictyostelium discoideum Ax2 cells (lane 8) were separated in SDS gels, transferred to nitrocellulose and processed for immunoblotting (lanes 1-4 or pll overlay (lanes 5-8). Western blots were performed using anti-p36 (lane 1) and anti-p11 (lane 2) monoclonals 111 or polyclonal antibodies directed against annexin consensus peptides (lanes 3,4 ). The sequences of the peptides represent a consensus of the endonexin folds present in annexin repeats II (CP2, lane 3 ) or IV (CP4, lane 4), respectively $|13|$. The p 11 overlay was carried out by incubating the nitrocellulose filters in a solution containing $5 \mu \mathrm{g}$ of human $\mathrm{p} 11 / \mathrm{ml}$ in $1 \%(\mathrm{w} / \mathrm{v})$ bovine serum albumin. $150 \mathrm{~mm}-$ $\mathrm{NaCl}, 25 \mathrm{~mm}-\mathrm{Tris} / \mathrm{HCl}, \mathrm{pH} 7.5$. After washing, bound $\mathrm{pll}$ was detected using the anti-p 11 monoclonal and peroxidaseconjugated anti-mouse immunoglobulins as second antibodies. In the p 11 overlay, purified porcine annexin II served as a positive control (lane 5 ).
While the monoclonal antibodies failed to detect crossreacting polypeptides in Xenopus, polyclonal antibodies directed against annexin consensus peptides [13] recognize annexin-like proteins at around 32 and $36 \mathrm{kDa}$ (Fig. 1, lanes $3,4)$. To assess whether one of these polypeptides represents the Xenopus homologue of annexin II, we performed a pl1overlay experiment. Owing to the high specificity of the p11annexin II interaction, the pl 1 overlay should unambiguously identify annexin II, once the pll-binding site in the $N$ terminal tail of annexin II is able to refold properly after SDS/gel electrophoresis and transfer to nitrocellulose. Figure 1 demonstrates that this is indeed the case. Immobilized procine annexin II binds human pl 1 which is present in the overlay solution and detected after binding by a pll monoclonal antibody (lane 5). If the same experiment is performed on total Xenopus proteins which were separated in SDS gels and transferred to nitrocellulose, a single polypeptide which co-migrates in the SDS gel with human annexin II is decorated (lane 7). In contrast, when total cellular proteins from Drosophila melanogaster (lane 6) or Dictyostelium discoideum (lane 8) are treated in the identical way, no pl 1 -binding protein is detected. Thus $X$. laevis cells contain a protein of around $36 \mathrm{kDa}$ which is recognized by antibodies against two different annexin consensus peptides and interacts specifically with human $\mathrm{p} 11$. The data suggest that this Xenopus annexin II has a highly conserved pl1binding site, since it interacts with human p 11 . Based on this conservation it seems likely that Xenopus cells also express a pll analogue which could bind to and thereby regulate the Xenopus annexin II.

\section{Annexin II is highly conserved among species}

Given the immunological and biochemical evidence for the existence of annexin II in chicken and Xenopus, we attempted to isolate the corresponding cDNA clones from $\lambda$ phage libraries. A full-length cDNA clone for chicken annexin II was obtained by screening a chicken embryo fibroblast cDNA library in $\lambda \mathrm{gt} 11$ (kindly provided by $D r R$. Hynes, M.I.T., Cambridge, U.S.A.) with both a monoclonal antibody directed against porcine annexin II (see above) and a human annexin II cDNA probe. The chicken cDNA clone has a length of 1370 nucleotides and contains a 1017 nucleotide open-reading frame which codes for 339 amino acids. Both the nucleotide and the translated amino acid sequence of the open reading frame are remarkably similar to the corresponding human $\{14\}$, bovine $[15\}$ and murine [16], annexin II sequences. The identities range between 80 and $90 \%$ at the nucleotide level and are around $90 \%$ at the amino acid level, respectively.

A human annexin II cDNA probe was also used to screen at low stringency a $\lambda \mathrm{gt} 10 \mathrm{cDNA}$ library made from Xenopus kidney cell RNA (kindly provided by Dr I. Mattaj, E.M.B.L., Heidelberg, F.R.G.). This approach led to the isolation of a full-length cDNA clone for Xenopus annexin II. This clone (1210 nucleotides in length) has an open-reading frame of 1020 nucleotides encoding a polypeptide of 340 amino acids. When compared with annexin II from other species, the Xenopus protein also shows a high degree of sequence conservation, with amino acid identities ranging from 80 to $85 \%$.

A close examination of the different protein sequences reveals that most of the annexin repeats, as well as the $N$ terminal 14 residues, i.c. the p 11 -binding domain, are particularly highly conserved. Species-specific differences in the primary structure cluster in a region between amino acids 15 and 41 , i.e. the 'hinge' region connecting the pl 1 -binding site and the first annexin repeat. Interestingly, this portion of the molecule is easily accessible to proteinases and contains all the major phosphorylation sites. Therefore, it seems that the hinge region resides on the outside of the protein showing no 
extensive higher-order structure. Owing to the existence of various phosphorylation sites it might, however, represent an important regulatory region. This notion is supported by the finding that within the native annexin II, residues at positions around 26 and 65 are in close proximity and form the discontinuous epitope for a monoclonal antibody [17]. Thus, the hinge region is in close contact to the endonexin fold of the first repeat, which is believed to serve as an important site for the interaction with $\mathrm{Ca}^{2+}$ and/or phospholipids.

\section{pll shows a higher degree of sequence variations among species}

To identify evolutionarily conserved portions within the pl1 sequence which are likely to serve as structurally important regions and/or contact sites for annexin II, cDNA clones for $\mathrm{pl} 1$ were isolated from different species. Using as probes synthetic oligonucleotides whose sequences were derived from the porcine $\mathrm{p} 11$ protein sequence [12], a cDNA clone for human pll was isolated from a $\lambda \mathrm{gt} 10 \mathrm{cDNA}$ library made from HT 29 (a human adenocarcinoma cell line) mRNA (kindly provided by Dr D. Louvard, Pasteur Institute, Paris, France). The human p11 cDNA was in turn used as a hybridization probe to screen the above-mentioned chicken and Xenopus cDNA libraries at low stringency. Sequence analysis of the cDNA clones obtained revealed that both the human and chicken cDNAs encode a protein of 96 amino acids, whereas the Xenopus pl 1 clone codes for a protein which comprises only 95 residues. While mammalian $[12,18]$ and chicken p1 1 are highly homologous (around $90 \%$ identities at the protein level), Xenopus pll shows a considerably larger degree of sequence variations with the identities limited to around $60 \%$ as compared with the other species. Most differences are found in the $N$-terminal-half of the molecule and none of them re-installs a functional EFhand. Since Xenopus annexin II is able to bind human p1l and contains a highly conserved pl1-binding site, it seems likely that the annexin II-binding site in Xenopus $\mathrm{p} 11$ is similarly highly conserved. This makes the second half of the p1 1 molecule a prime candidate for this binding site.
Taken together, the sequence data presented here point to an important physiological role of annexin II, since this polypeptide is highly conserved among different species. Within the protein sequence, the endonexin folds in all four annexin repeats are particularly well conserved. Mutational analysis should further clarify whether the endonexin fold indeed represents the binding site for $\mathrm{Ca}^{2+}$ and/or phospholipid.

1. Glenney, J. R. (1988) BioEssays 7, 173-175

2. Klee, C. B. (1988) Biochemistry 27, 6645-6653

3. Gerke, V. (1989) Cell Motil. Cytoskeleton 14, 449-454

4. Crompton, M. R., Moss, S. E. \& Crumpton, M. J. (1989) Cell (Cambridge, Mass.) 55, 1-3

5. Burgoyne, R. D.\& Geisow, M. J. (1989) Cell Calcium 10, 1-10

6. Brugge, J. (1986) Cell (Cambridge, Mass.) 46, 149-150

7. Powell, M. A. \& Glenney, J. R. (1987) Biochem. J. 247, 321-328

8. Drust, D. S. \& Creutz, C. E. (1988) Nature (London) 331 , $88-91$

9. Johnsson, N., Marriott, G. \& Weber, K. (1988) EMBO J. 7 , 2435-2442

10. Kligman, D. \& Hilt, D. C. (1988) Trends Biochem. Sci. 13, $437-443$

11. Osborn, M., Johnsson, N., Wehland, J. \& Weber, K. (1988) Exp. Cell Res. 175, 81-96

12. Gerke, V. \& Weber, K. (1985) EMBO J. 4, 2917-2920

13. Gerke, V. (1989) FEBS L.ett. 258, 259-262

14. Huang, K., Wallner, B. P., Mattaliano, R. J., Tizard, R., Burne, C., Frey, A., Hession, C., McGray, P., Sinclair, L. K., Chow, E. P., Browning, J. L., Ramachandran, K. L., Tang, J., Smart, J. E. \& Pepinsky, R. B. (1986) Cell (Cambridge, Mass.) 46, 191-199

15. Kristensen, T., Saris, C. J. M., Hunter, T., Hicks, L. J., Noonan, D. J., Glenney, J. R. \& Tack, B. F. (1986) Biochemistry 25 , 4497-4503

16. Saris, C. J. M., Tack, B. F., Kristensen, T., Glenney, J. R. \& Hunter, T. (1986) Cell (Cambridge, Mass.) 46, 201-212

17. Johnsson, N., Johnsson, K. \& Weber, K. (1988) FEBS Lett. 236, 201-204

18. Saris, C. J. M., Kristensen, T., D'Eustachio, P., Hicks, L. J., Noonan, D. J., Hunter, T. \& Tack, B. F. (1987) J. Biol. Chem. 262, 10663-10671

Received 13 July 1990

\section{Annexins: a subcellular localization and reconstitution approach to elucidate cellular function}

\section{A. KAETZEL, ${ }^{*}$ P. HAZARIKA, ${ }^{*}$ M. DIAZ-MUNOZ, $\dagger$ W. DUBINSKY, ${ }^{*}$ S. L. HAMILTON† and J. R. DEDMAN* * Department of Physiology and Cell Biology, University of Texas Medical School, Houston, TX 77225, U.S.A. and †Department of Molecular Physiology and Biophysics, Baylor College of Medicine, Houston, TX 77030, U.S.A.}

The goal of our laboratory has been to elucidate the cellular pathways used to mediate and discriminate the intracellular $\mathrm{Ca}^{2+}$ signal. Our approach has been to identify, purify and characterize $\mathrm{Ca}^{2+}$ binding proteins with regard to tissue specificity, and cellular and subcellular localization. Using this collective information, biochemical reconstitution experiments can be designed to elucidate the cellular function of the individual $\mathrm{Ca}^{2+}$ mediator proteins. The fact that $\mathrm{Ca}^{2+}$ regulates a wide variety of cellular activities suggests that this complex mechanism of regulation would include multiple $\mathrm{Ca}^{2+}$ pathways with differential expression of the independent mediator proteins.

Several laboratories have independently identified a group of $\mathrm{Ca}^{2+}$-binding proteins through their $\mathrm{Ca}^{2+}$-dependent binding to cytoskeletal elements, isolated membranes, secre-

Abbreviation used: SR, sarcoplasmic reticulum tory granules or hydrophobic resins. Sequence data indicate that there are eight unique gene products, each of which is composed of four or eight repeats of a motif of 60-70 amino acids. These $\mathrm{Ca}^{2+}$ /phospholipid-binding proteins have been designated as annexins I-VIII $[1,2]$. This superfamily is not related to calmodulin, troponin $\mathrm{C}$ and protein kinase $\mathrm{C}$ with regard to potential structural mechanisms of binding calcium and phospholipid. Although sequence information on these proteins is complete, their cellular roles have not been defined $[3,4]$. We have utilized subcellular localization studies to focus on possible cellular functions of the $35 \mathrm{kDa}$ and $67 \mathrm{kDa}$ calcimedins, that is, annexins III-VI.

Annexins III, IV, V and VI (calcimedins $35 \alpha, 35 \beta, 35 \gamma$ and 67) were identified and purified by $\mathrm{Ca}^{2+}$-dependent phenyl-Sepharose and DE-52 of Mono Q h.p.l.c. chromatography $[5,6]$. The proteins were injected into sheep and the antibodies antigen-affinity purified. To identify whether the $35 \mathrm{kDa}$ calcimedins were annexins, an antibody was produced against the annexin consensus sequence, K-A-M-K-GL-G-T-D-E; this represents a sequence found in all members of the annexin family [2]. This consensus sequence antibody cross-reacts with annexins I, II, III, IV, V and VI, but not with $30 \mathrm{kDa}$ and $32 \mathrm{kDa}$ calcimedins or calmodulin [2].

Our initial step to identify annexin function was to use 